\title{
Systems Analysis - a new paradigm and decision support tools for the water framework directive
}

\author{
M. Bruen \\ Centre for Water Resources Research, University College Dublin, Newstead, Belfield, Dublin 4, Ireland
}

Received: 23 May 2007 - Published in Hydrol. Earth Syst. Sci. Discuss.: 12 June 2007

Revised: 3 March 2008 - Accepted: 7 April 2008 - Published: 15 May 2008

\begin{abstract}
In the early days of Systems Analysis the focus was on providing tools for optimisation, modelling and simulation for use by experts. Now there is a recognition of the need to develop and disseminate tools to assist in making decisions, negotiating compromises and communicating preferences that can easily be used by stakeholders without the need for specialist training. The Water Framework Directive (WFD) requires public participation and thus provides a strong incentive for progress in this direction. This paper places the new paradigm in the context of the classical one and discusses some of the new approaches which can be used in the implementation of the WFD. These include multicriteria decision support methods suitable for environmental problems, adaptive management, cognitive mapping, social learning and cooperative design and group decision-making. Concordance methods (such as ELECTRE) and the Analytical Hierarchy Process (AHP) are identified as multi-criteria methods that can be readily integrated into Decision Support Systems (DSS) that deal with complex environmental issues with very many criteria, some of which are qualitative. The expanding use of the new paradigm provides an opportunity to observe and learn from the interaction of stakeholders with the new technology and to assess its effectiveness.
\end{abstract}

\section{Introduction}

The EU Water Framework Directive (WFD) requires that every country introduce measures to improve and sustainably maintain good chemical water quality and ecological status by 2015 . All tools that can improve chemical and ecological status may be implemented and this includes physical intervention (e.g. hydro-morphology), social interaction (e.g. education and outreach influencing behaviour), economic instruments and legislation. Regardless of any scientific and economic justification, it is unlikely that all proposed measures or policies will be acceptable to all stakeholders so that considerable controversy and some planning and legal challenges can be expected. Consultation, negotiation, compromise and refinement of measures can be expected. Thus it is imperative that all decisions on policy and measures be taken not only (i) on the basis of the best available scientific and economic information but also (ii) be taken using an unbiased, independent and logical methodology and (iii) take account of all stakeholders concerns, both quantifiable and non-quantifiable, in a transparent manner. This requires the "systems approach" to decision making. Given the complexity of the scientific processes and computer models involved, a computer-based decision support system with multi-criteria analysis capability is an essential tool in such a decision-making chain. It must have access to the best information on available measures and it must be able to interact with stakeholders (two way communication) to reliably gauge their opinions and preferences and to incorporate them in the decision analyses. This paper starts with a description (in Sects. 2 and 3) of how the classical systems approach to decision making in relation to large infrastructural projects has, in practice, expanded to include feedback loops involving negotiation, compromise and possibly revision of priorities. Then, in Sect. 4, some new analysis tools and methods are described which support the new paradigm. Finally, Sect. 5 describes briefly some examples of the new types of decision support systems that have emerged to facilitate the use of these new methods by all types of stakeholder.

Correspondence to: M. Bruen

(michael.bruen@ucd.ie)

Published by Copernicus Publications on behalf of the European Geosciences Union. 


\section{Systems approach - the classical paradigm}

De Neufville (1990) defined systems analysis as "the use of rigorous methods to help determine preferred plans and designs for complex, often large-scale systems. It combines knowledge of the available analytic tools, understanding of when each is more appropriate, and skill in applying them to practical problems. It is both mathematical and intuitive as is all planning and design." Ossenbrugger (1984) defined it as "a coordinated set of procedures that can be used to address issues of project planning, engineering design and management. Systems Analysis is a decision making tool. An engineer can use it for determining how resources can be used most efficiently and most effectively to achieve a specified goal or objective." Burus (1972) declared it to be "an extension of the scientific method and it introduces into it a certain degree of formalism, which channels the thinking and guides it through the maze stretched between formulation of objectives and performance of the design".

All of these definitions focus on the toolbox aspect of the discipline, the collection of appropriate mathematical and numerical tools for solving practical problems, that came to be classified as "hard" systems. Major issues relating to uncertainties in the objectives and criteria and how to deal with multiple decision makers (or stakeholders) with competing objectives did not arise at that stage. A fixed and knowable set of objectives was assumed although it was recognised that some effort may be required to generate the complete set. A rational and unwavering decision maker was also usually assumed.

When systems analysis was applied to water resources projects and river basin management, the projects often related to very large scale measures, involving significant infrastructural, policy or legislative changes, and it was considered desirable to formalise the various activities involved in making decisions about the design and/or management of such measures. The classical paradigm for such a systematic approach to decision making contains the following five steps:

\subsection{Definition of objectives}

The objectives of the project are specified. For a commercial project, the "client's" objectives are paramount, maximise profit or shareholders' value in a Public Company. However, in the context of European Directives (and not just the WFD), the issue is more complex. It would be too easy to say it is the "stakeholders" objectives that should count. However, the WFD envisages stakeholders having an advisory role and it is typically a government department or organisation which implements and pays for the WFD measures so that their objectives are important and must be considered. A complicating factor is that large-scale water resources problems usually involve a very wide range of objectives and have a wide range of significant benefits and impacts and corresponding assessment criteria. While many of the objectives will map to specific objectives of the WFD, there will be others, such as "equity", "national or regional development" which are obvious concerns for the implementing authorities.

\subsection{Establish measures of effectiveness}

Procedures must be established for assessing each objective or criteria. They may be quantitative (e.g. cost) or qualitative (e.g. visual impact, taste etc.). In most cases there are many different ways to assess any one objective. For instance for any physical quantity a criterion could be a long term average, a mean daily average (or over any period) or the number or duration of exceedences of a threshold. The choice of measure can unintentionally bias the decision making process. The assessment may be qualitative or quantitative.

\subsection{Generation of alternatives}

A list of possible types of solution is generated. In the context of the WFD these are the "measures". The list should be as complete as possible and cover all the possible categories of measures. Typically the more people contribute to the discussion the longer the list.

\subsection{Evaluation of alternatives}

All of the possible types of solution are evaluated in relation to the measures of effectiveness for each criterion. This invariably requires modelling and simulation which produces an assessment matrix with an assessment for each criteria for each alternative (measure).

\subsection{Decision or recommendation}

The results of the evaluation are analysed and decisions or recommendations are formulated. When there are many objectives/criteria this may require some trade-off between objectives and multi-criteria decision support techniques can help here.

This classical paradigm, illustrated in Fig. 1 is a linear procedure. The final two steps depend on the results of the three preceding ones so the steps must be completed in the order indicated.

\section{A new paradigm}

The classical paradigm was fostered by the General Systems Theory approach to understanding complex systems that evolved in the 1940s (Bertalanffy, 1968) and by the subsequent need to manage such systems in a "real-world" context (Checkland, 2000). Checkland (2000) considered that General Systems Theory had "failed", but perhaps this was only because too much was expected by its originators. It strongly influenced work on ecological systems simulation (Odum, 1994 and Odum and Odum, 2000) and the 


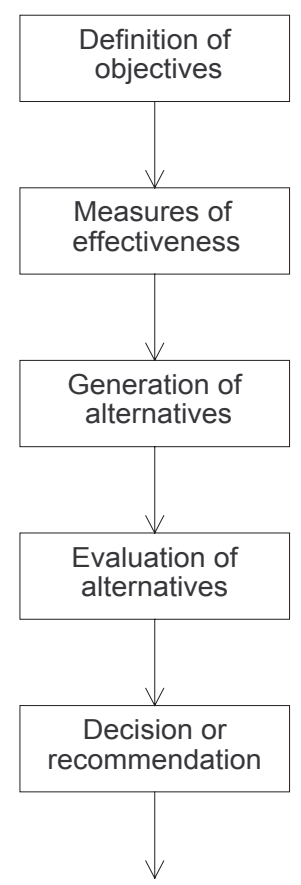

Fig. 1. Systems approach: Classical Paradigm (Bruen, 2006).

ecosystem diversity-stability controversy sparked by May (1984). While Bertalanffy differentiated between "closed" and "open" systems, depending on whether the system could be considered in isolation from its surroundings (with environmental systems generally placed in the latter category) the classical paradigm is more appropriate for closed, welldefined, systems. While it is still valid today in certain circumstances, it does have some fundamental limitations, particularly when applied to complex problems with many important environmental considerations, as with the WFD. This is because of the assumed "closed" nature of the problem, for instance that the decision maker(s) are readily identifiable from the beginning and that their priorities can be readily obtained at the beginning of the analysis and that they do not change over appreciable time scales and are not influenced by the decision process itself. This may be true in many circumstances, for instance for most private companies and for some public agencies. However, many decisions relating to large-scale activities or measures related to the WFD have significant environmental impacts and the objectives and priorities of, and impacts on, the general public may not be easy to obtain in the "abstract" initial stages of the analysis. The author believes that many people are better able to appreciate the issues and articulate their opinions when faced with a single specific design proposal to consider. Moreover, priorities and opinions may change over the time-scales envisaged for the implementation of the WFD and may be influenced by involvement with the decision making process. Thus the steps shown in Fig. 2 better represent what happens in practise. It

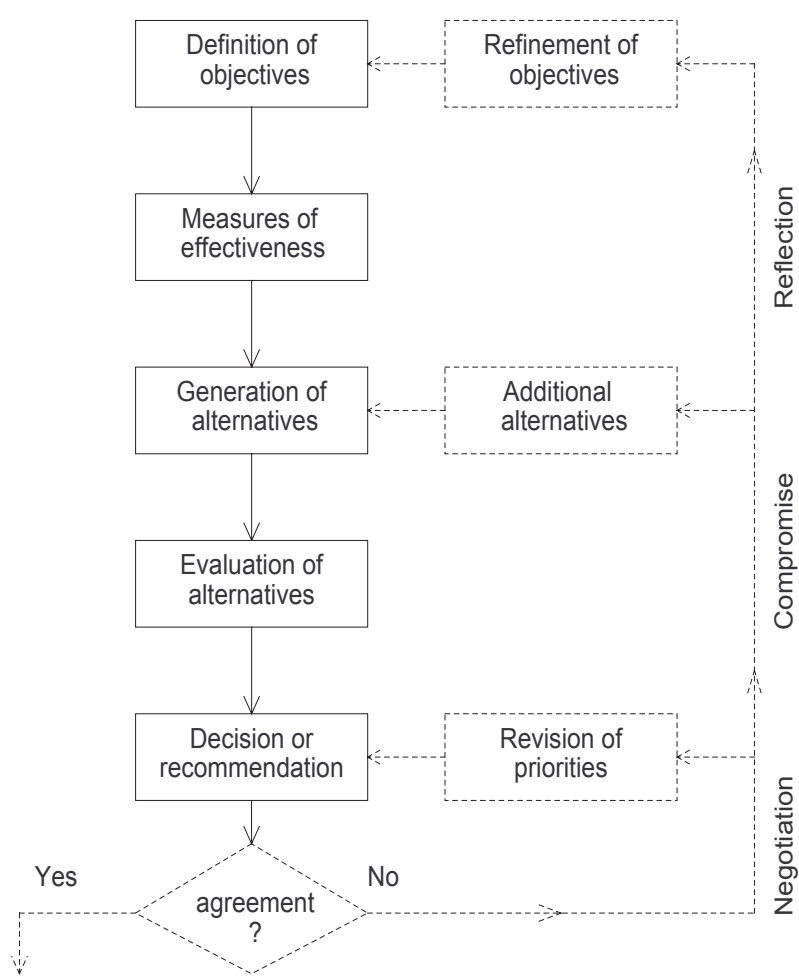

Fig. 2. Systems approach: New Paradigm (Bruen, 2006).

is an iterative one in which some feedback from stakeholders is possible after a preliminary "solution" has been proposed. This feedback may lead to a revision of priorities, or to additional alternatives (measures), typically compromises between or combinations of the original ones. The learning process involved may even lead to some refinement of the objectives. The ultimate aim is to find an acceptable compromise between the various, invariably competing, objectives, and this involves negotiation, compromise and perhaps even some rethinking of the project objectives. This was recognised at a comparatively early stage, e.g. by Jamieson (1986) who wrote "River basin management can be characterised as an exercise in conflict resolution". More recently, Wilson and Droste (2000) describe the changing role of analysis and negotiation in environmental decision-making. They identify the need for a new look at the information technology requirements of decision support in the area of water resources. They stress that integration of key management functions should be linked to the Decision Support System (DSS).

\section{New tools for the new paradigm}

\subsection{Introduction}

In the classical paradigm, computers were used to a significant degree in the fourth stage "Evaluation of alternatives" 
and to some degree in the fifth "Decision or recommendation". This is because the evaluation generally required predicting future performance and this required numerical simulation models. All the various numerical modelling tools were available and there was a broad choice of specialist simulation software packages for both continuous and discrete systems, e.g. GPSS (General Purpose Simulation System) (see http://www.webgpss.com) or STELLA (Structural Thinking Experiential Learning Laboratory with Animation) (Hannon and Ruth, 1994). Some general purpose optimisation methods (see Gill et al. (1981) for the classical techniques and Efstratiadis and Koutsoyiannis (2002) for some examples) could be used in the fifth stage to produce decisions that were optimal in relation to a single criterion. More recently however, new decision support techniques have been developed to assist with the more complex decision problems typically associated with environmental issues, Bruen (1999) and also with the additional stages (particularly negotiation and compromise) associated with the new paradigm shown in Fig. 2. Some of these, particularly those with most promise for use in implementing the WFD, are described below. The choice of methods is based on the author's practical experience and ongoing research in the water/environmental area.

\subsection{Generation of alternatives}

Although the "Generation of alternatives" is an activity required by the classical paradigm, a number of very useful techniques have emerged that improved on the more traditional "brainstorming" techniques (Osborne, 1963). For instance, De Bono developed a systematic approach to promoting Lateral thinking (de Bono, 1967) and reported that good results are possible from managed group interactions, such as with Metaplan (www.metaplan.com). This is a technique that divides the contributors into small isolated groups (producing multiple channels of communication) and encourages participation by using cards and a facilitator trained to encourage and manage discussions. It has been used by the author in hydrological applications as diverse as the Aral Sea Environmental catastrophe (unpublished) and end-user requirements for flood forecasting systems (Bruen, 2005).

\subsection{Multi-criteria methods}

The WFD requires the involvement of stakeholders in the decision making process. In relation to water quality and ecology, a very broad and diverse range of stakeholders are involved and a correspondingly broad range of decision criteria (or project objectives) are involved. Many multi-criteria methods were developed to manage and to formalise the resulting decision making process, however three methods are particularly useful - Multi-attribute utility; the Analytic Hierarchy Process; and the Concordance group of methods (Rogers and Bruen, 1995) and are described below. All are existing techniques that came to prominence within the last two decades.

\subsubsection{Multi-Attribute Utility Methods (MAUT)}

One of the earliest approaches to the multi-criteria decision problem was to extend the existing utility theory to multiple dimensions. (Keeney and Raiffa, 1993) Utility was originally used by economists (see Galbraith (1991) for a short history - it was mentioned by Bentham in 1789) and represents a person or group's level of satisfaction with a particular outcome and can be used to indicate preference or indifference between the outcomes or consequences of any policy. Its use requires some strong assumptions about the nature of the decision-maker's preference structure and is expressed on an ordered metric scale. The numbers of this scale have no absolute physical meaning and the scale is constructed by assigning arbitrary numbers to any two points. Typically these points correspond to the best (utility $=1$ ) and worst (utility = 0) possible outcomes.

In many cases the decision problems facing engineers and planners involve a large number of different types of criteria. In particular, decisions based on Environmental Impact Assessments may involve a very large number of types of consequences relating to water, air, noise, amenity, landscape, flora, fauna etc. In principle the same utility theory developed for the single decision attribute can be directly extended to cover such cases. Multi-Attribute Utility Theory (MAUT) (Keeney and Raiffa, 1993) generalises the concept of utility to any number of criteria and allows possible consequences to be "traded off" against one another, while also taking account of their probabilities of occurring. The closely related ideas of value and utility have a long history, starting in the field of economics, but are now used in a wide variety of decision-making contexts. For instance, engineers and planners use them when considering alternatives for large-scale projects; especially those related to infrastructure development. Economists use them when analysing the operation of enterprises, markets and economies and especially in the field of welfare economics. Psychologists and social scientists use them in the study of peoples' behaviour and the reasons for the choices they make. The aim is to improve understanding of peoples' preferences and to develop tools to assist in choosing policies consistent with these preferences. It is tacitly assumed that such decisions are good ones and that they will be accepted by a large number of the people affected by them.

\section{MAUT as a direct extension of utility theory for a single criterion}

In principle the multi-attribute utility function can be measured by a direct extension of the way it is done for a single attribute utility function. The utility for two arbitrary reference points is defined and the utility for all other points 
can be estimated in relation to these. For $\mathrm{N}$ criteria, the amount of information required to define the utility function increases in proportion to the power of $\mathrm{N}$, and the amount of data required becomes prohibitive, even for relatively small numbers of criteria and especially for decisions with large numbers of environmental impacts.

For example, suppose that 5 points could adequately represent the utility function for a single criterion. If there were two criteria then the utility function would be a two dimensional function and $5^{2}-2$ or 25 points less the 2 fixed points would be required to represent the utility function with a corresponding level of accuracy. If there are three attributes then $5^{3}-2$ or 123 points are required to represent the function with the same resolution. It is easily seen that the latter would require extensive surveys and interviews making it prohibitively expensive. Even the two dimensional case requires considerable effort if tackled in the direct way. For instance, if the utilities of each criterion are independent of the others then the multiattribute utility function is constructed as a weighted average of the utility functions for each individual attribute (consequence), i.e.

$U(X)=\sum_{\text {all } i} w_{i} u_{i}\left(x_{i}\right)$

where, $X=\left(x_{1}, x_{2}, \ldots, x_{n}\right)$ is an n-element vector of criteria values, $\mathrm{U}(\mathrm{X})$ is the multivariate utility function and $u_{i}\left(x_{i}\right)$ is the univariate utility function for the $i$ th criterion. The $w_{i}$ are weights which specify the relative contribution of each criterion in the final decision. They are assumed to be fixed regardless of the magnitude of the criterion value and also are independent of the other criteria (cf. Vincke, 1992). In many practical situations however, the utilities of some criteria are influenced by other criteria and the simple weighted average approach cannot be used. Keeney and Raiffa (1993) developed an approach in which the multivariate utility function can be related to the individual utility functions by the equation

$K U(X)+1=\prod_{i=1}^{n}\left\{1+K k_{i} u_{i}\left(x_{i}\right)\right\}$

where, both $U(X)$ and the $u_{i}\left(x_{i}\right)$ are scaled so that 0 represents the worst possible situation and 1 the best possible situation. A good introduction to the application of MAUT is given in De Neufville (1990).

\subsubsection{Analytic Hierarchy Process (AHP)}

The Analytical Hierarchy Process (Saaty, 1980) is a multicriteria decision support method based on qualitative pairwise comparison data (typically obtained from a questionnaire survey of decision makers or experts). It is essentially a formal expression of the decision maker's understanding of a complex problem using a hierarchical structure, that separates the problem into its natural components (criteria and
Table 1. Saaty's preference scale (after Saaty, 1980).

\begin{tabular}{lc}
\hline Preference & value \\
\hline absolutely preferable & 9 \\
very strongly preferable & 7 \\
strongly preferable & 5 \\
mildly preferable & 3 \\
equal importance & 1 \\
\hline
\end{tabular}

alternatives) and links them (via weights and expert assessments) to the final decision. Thus, it reduces a decision problem to a series of smaller self-contained analyses. The relative merit of each policy alternative is determined from a pair-wise analysis of the relative performance ratings for all combinations of alternatives, separately for each criterion. The relative importance of each criterion can also be determined from a similar pair-wise analysis of decision makers' preferences. The result of the overall process is a ranking of all alternatives on an interval scale. Dividing the problem into a hierarchy that explicitly separates criteria and alternatives has many advantages. They can be used to describe how changes in priority or assessment at upper levels affect priorities of elements in lower levels. They provide detailed information on both the structure and function of the system, they are stable and flexible, and they can mirror reality, since most natural systems are assembled hierarchically.

A hierarchy has at least three levels: the focus or overall goal of the decision problem at the top, multiple criteria in the middle layer, and competing alternatives at the bottom (measures for the WFD). Saaty (1977) suggests using a simple nine point numerical scale, such as the one given in Table 1, to represent the results of each pair-wise comparison. This is supported by psychological studies (Miller, 1956) that show that a scale of about 7 points is sufficiently detailed. Saaty noted that the ability to make qualitative decisions was well represented by five verbal attributes (equality, weak preference, strong preference, very strong preference and absolute preference).

For example, given four elements $\mathrm{A}, \mathrm{B}, \mathrm{C}$ and $\mathrm{D}$ within one hierarchy level, each pair - AB, AC, AD, BC, BD, and $\mathrm{CD}$ - is directly compared with respect to its influence on $X$. If, for instance $A$ is mildly preferable to $B$ then the number 3 is placed in the cell at the intersection of the row corresponding to A with the column corresponding to B. Its reciprocal is placed in the symmetrically opposite cell. Inserting all the possible pair-wise comparisons gives a matrix with a structure as in Table 2.

Note that

$a_{j, i}=\frac{1}{a_{i, j}}$

Saaty showed that the importance weights can be determined 
Table 2. Pair-wise comparison reciprocal matrix for Analytical Hierarchy Process.

\begin{tabular}{ccccc}
\hline & $\mathrm{A}$ & $\mathrm{B}$ & $\mathrm{C}$ & $\mathrm{D}$ \\
\hline $\mathrm{A}$ & 1 & $a_{1,2}$ & $a_{1,3}$ & $a_{1,4}$ \\
$\mathrm{~B}$ & $\frac{1}{a_{1,2}}$ & 1 & $a_{2,3}$ & $a_{2,4}$ \\
$\mathrm{C}$ & $\frac{1}{a_{1,3}}$ & $\frac{1}{a_{2,3}}$ & 1 & $a_{3,4}$ \\
$\mathrm{D}$ & $\frac{1}{a_{1,4}}$ & $\frac{1}{a_{2,4}}$ & $\frac{1}{a_{3,4}}$ & 1 \\
\hline
\end{tabular}

from this matrix by determining the eigenvector corresponding to its largest eigenvalue, a standard numerical procedure. In the water resources area, the technique has been used for optimal choice of sewerage treatment process for a high capacity but limited area site in Hong Kong (Tang and Ellis, 1991), catchment management (de Steiguer et al., 2003; Heathcote, 1998) and has been used in conjunction with other methods such as social choice theory (Srdjevic, 2007). However, Triantaphyllou (2001) reports some inconsistent behaviour in additive version of AHP.

\subsubsection{Concordance analysis}

Concordance Analysis is a non-compensatory multi-criteria decision support method which indicates the degree of dominance (if any) of any one policy over others (Massam, 1988). The method does not necessarily produce a strict ranking of all the alternatives and some can remain incomparable with some others. For example, if some alternative "a" is better than both "b" and "c", it becomes irrelevant to analyse preferences between $b$ and $c$ and they need not be compared without invalidating the choice of "a". In Concordance Analysis, there is no question of the 'trading-off' of one criterion directly against another for each individual alternative. Comparison between alternatives proceeds on a pair-wise basis with respect to each criterion, and establishes the degree of dominance that one alternative has over another. One of the most commonly used methods within Concordance Analysis, the ELECTRE Method, (Elimination et choix traduisant la réalité) was originally developed by Bernard Roy (Benayoun et al., 1966). It involves a systematic analysis of the relationship between all possible pairings of the different alternatives, using their scores on a common set of criteria. The result is a measure of the 'outranking' of one alternative over another. While ELECTRE has no axiomatic basis, and can involve professional judgement, it nonetheless provides a valuable framework for examining multi-criteria problems. In the water resources area it has been used in the selection of projects for rural (Roy et al., 1992) and urban (Kodikara et al., 2005) water supply.

Initially, multi-attribute utility theory (MAUT) was used as it had a strong mathematical axiomatic basis (Keeney and Raiffa, 1993). However doubts were expressed about the ap- plicability of its assumptions to the human decision maker or stakeholder. However the effort required establishing utility curves in MAUT does not scale well as the number of criteria increases and the method was difficult to apply to environmental problems with typically large numbers of criteria and mixtures of qualitative and quantitative. The alternative methods described above were developed to cater for these two complicating factors, such as AHP (Saaty, 1980) and ELECTRE (Rogers et al., 1995, 1998). A large range of applications in the water resources area has recently been reviewed by Hajkowicz and Collins (2007) who confirm that paired-comparison (e.g. AHP) and ELECTRE type methods are the most widely used. However, Wang and Triantaphyllou (2008) report problems with anomalous rank reversals in ELECTRE 2 and 3 in specific cases.

\subsection{Adaptive management}

Adaptive management is based on an acceptance that the uncertainties in water resources systems, including its human components, and its external drivers, such as climate change (Pahl-Wostl, 2007a), preclude accurate prediction of the future and thus also preclude attempts at optimal long term policy-making ab initio. A natural alternative is to move into the future in a series of short-term steps each of which includes not only policy formulation but also information gathering to assess the impact of existing policy and help to improve it at the subsequent step (Pahl-Wostl, 2007b). It is, in effect, the "Kalman Filtering" of policy formulation. This is a numerical procedure for regularly updating estimates of the state of a system as new information becomes available (Kalman, 1960). Its particular strength is in dealing in an optimal way with the uncertainties in both the new information and in knowledge of how the system evolves in time. Adaptive management envisages an analogous regular updating using new information gathered about the behaviour of the system from its response to previous actions. It extends the approach by allowing for the development of shortterm strategies to test various critical hypotheses about the response of the entire socio-eco-hydrological system with the aim of ultimately improving the long-term strategy. This is because long-term optimality may be better served by an initial strategy designed to gain information about the system and its response rather than designed only for best initial step towards the goal of "achieving good water and ecological status" as soon as possible. However, in practice there may be some resistance to implementing such an approach. In addition, its appropriateness depends on the current state of knowledge about water resources, which varies considerably between EU member states. Sharma and Norton (2005) describe its use in policy formulation in relation to climate change and stress that such methods must take account of how the public response to policy has a role in shaping public attitudes. However, the WFD is structured in a way that allows for adaptive management since its article 13(7) provides 
for regular review and updating of Water Management Plans on a 6 years cycle.

\subsection{Social learning}

Tippett et al. (2005) point out that while "it is individuals who learn, they do so in social groups" and thus this knowledge is social. They define social learning as "organisational learning that results in enhancing a group's ability to change its underlying dynamics and assumptions" and point out that this is necessary for an adequate response to WFD requirements, given the complexity of the systems being managed. This process is thus a natural adjunct to adaptive management. Ison and Watson (2006) describe how social learning can be applied to the implementation of the WFD in Scotland. The key element is that cooperative behaviour is promoted by learning that is facilitated by institutional support. This is supported by a comparison of their own experience in Scotland with the situation in other juristictions.

\subsection{Cognitive mapping}

Cognitive mapping (Eden, 1990), which is based on the theory of personal constructs (Kelly 1955), is a technique to organise, analyse and make sense of descriptions of problems or systems. Cognitive maps are often determined from interviews with stakeholders and they describe how the interviewees represent internally the external environment (Kearney and Kaplan, 1997). It clarifies people's conceptions about their environment by recording them in diagrams showing the concepts and their interconnections. Giordano et al. (2005) applied fuzzy cognitive maps to develop a "water community cognitive map" used in negotiation between stakeholders and for conflict resolution relating to equity in water distribution during drought periods in Italy. Kolkman et al. (2005) pointed out that the complexity of environmental problems and the differences in the conceptualisations of the decision makers, stakeholders and scientists increase the difficulties of negotiation and reaching a consensus. They suggest using a "mental maps" approach to address this and give an example application to the design of the Zwolle storm barrier in the Netherlands. Tan and Ozesmi (2006) used the Fuzzy Cognitive Mapping technique to develop a comprehensive lake ecosystem model from the separate conceptualisations of 8 lake scientists. They found that, not only did it produce a good model, but the exercise provided insights that extended the knowledge of the participating experts in a practical way. Tippet et al. (2005) apply cognitive mapping to examine the objectives of forest users.

\subsection{Groups: cooperation, negotiation and compromise}

Giordano et al. (2006) describe cooperation between modellers and the public in developing simulation models to assist in decision making. They question the public participants about their experience of the modelling process and report their opinions on the credibility and value of the resulting model. Dinka and Lundberg (2006) studied the effect of personal identity on cooperation in design teams, noting a distinction between a participant's professional and personal role. Vatn (2007) explores the conditions and reasons for peoples' willingness to cooperate in relation to usage of resources. Starting from experiments in psychology and economics, he explores different conditions/structures that tend to produce cooperative behaviour (even when individual gain is sacrificed) and those producing a focus on individual gain. He advocates institution reform that encourages the active involvement of citizens. These include having a formal set of rules, a system for both rewarding cooperative behaviour and punishing selfish behaviour and an effective communications system. Regan et al. (2006) describe a mathematical consensus convergence model based on establishing consensus priority weights for individual groups. They note that, in group decision making, simple averages of individual stakeholders' weights or preferences can often lead to decisions not really representative of the group. They note that the size and composition of the group can influence an individual's response and, in particular, that special interest groups can acquire a high degree of influence. As a solution, they describe a mathematical procedure in which each member of a group is asked to assign weights reflecting the importance (they call it a "weight of respect") they give to the opinions of other members of the group. From these an importance ranking can be determined for each member of the negotiating group. Shirani (2006) compared the characteristics of face to face discussion within a decision making group with discussion mediated by a Group Support System (GSS). He found that GSS promoted sharing within the group of information known initially only to a few members of the group, compared to face to face discussions, in which specialised information was less likely to be passed on. Turoff et al. (2002) describe a "collaborative writing process" implemented on the internet, to assist in producing agreed documents and have developed such a system using the Java language that can be used via any web browser. Damart et al. (2007) describe how the ELECTRE TRI (ELimination Et Choix Traduisant la REalite - TRI stands for the 3rd variation) method can be used to support group decision making. The defining characteristic of the method is that it provides a formal procedure that allows the factors that support a particular choice (called "concordance") to be considered alongside the factors that oppose that choice (called "discordance"), Roy (1968). Janssen et al. (2006b) describe the use of a simple group decision support tool for land use management in the Netherlands. It allowed different interest groups to specify their preferred uses for all lands in a study area. The system produced maps that show where there was general agreement and also highlighted areas where there was strong conflict. These maps informed the ensuing negotiations between groups and were acknowledged by them as beneficial in communicating information. 
Innes and Booher (1999) describe the general conditions that facilitate consensus building; (i) the negotiating group should include representatives of all relevant and significantly different interests; (ii) The overall goals are real, practical and are shared by all members of the group; (iii) The group can regulate its own activities, e.g. defines its own procedures and rules; (iv) engages the participants and keeps them interested and involved; (v) encourages challenges to convention; (vi) produces high quality information that is trusted by the participants and (v) ensures that sufficient discussion of the issues takes place before consensus is sought. With the complex issues involved in the implementation of the WFD, the production of high quality, trusted, information is a task for decision support systems.

\section{DSS support}

The development of new "soft" techniques and approaches described above required a new set of supporting software tools. In the following sections some of these tools are briefly described. The choice of systems focussed on stakeholder communication and negotiation and thus many tools that are primarily numerical modelling systems were not included. Simplicity of user interface and potential for multiple use over the internet (to allow as wide a range of public participation as possible) were the most important criteria in selecting the systems described.

\subsection{For negotiation}

Tippett $(2004,2005)$ points out the challenges of the WFD and describes "SUNstainable DesignWays" tool and its role in fostering societal participation in forming decisions. The approach encourages and facilitates stakeholder involvement in planning sustainable solutions to development problems. A very graphical and hands-on approach, it combines elements of the system approach (described above) with ideas from sustainable ecology, environmental management, mind maps and multicriteria analysis. Typically participation is in groups creating or amending a plan, map, mind-map or activity diagram.

Decisionarium (http://www.decisionarium.hut.fi) (Hamalainen, 2003; Moreno-Jimenez and Polasek, 2003) is a public site for interactive multicriteria decision support with tools for individual choices, group collaboration and negotiation. It includes (a) Web-HIPRE (value tree and AHP analysis); (b) RICH (allows incomplete ordinal preference statements when considering the relative importance of attributes in a value tree); (c) Opinions-Online (a platform for surveys voting and group collaboration) ; (d) Joint Gains (to support multiparty negotiations in a multicriteria setting) and (e) Smart Swaps (an implementation of the even swaps procedure). All of the tools are web based so global interaction is easy and links can be utilized for multimedia information support.

TED: Towards Electronic Democracy: An e-negotiation system is proposed by the TED project, Rios-Insua et al. (2003), Rubio et al. (2005). It delivers modern methods of decision analysis and group decision support over the internet and makes it easier for the public to participate in decisions that affect them. This makes it easier to obtain, from a wider section of interested parties, the feedback that is essential for the negotiation and compromise phases shown in Fig. 2.

Haseman et al. (2005) describe a Group Decision Support System (GDSS) based on collective memory that uses hypermedia and groupware and intranet facilities. They report that the approach helps participants establish and communicate group norms. This was valuable when the groups were involved in sequences involving similar types of decision making situations. Limayem et al. (2006) consider reasons for some disappointing results. They conclude that although GDSS generally improves the decision making process, when it is not used correctly the results can be worse than for unassisted group decisions. The "e-Participation"” system of Lourenco and Costa (2007) focuses on collaborative writing which can produce consensus building and cooperation between groups or individuals. The intention is that the process would produce agreed documents reflecting different discourses as a useful and acceptable contribution to public decision processes. This is a highly transparent process and the intrinsic value of transparency in promoting the acceptance of the outcome of the decision process has been identified by Kemp et al. (2006), based on their UK experience of involving stakeholders in decisions relating to Best Practical Environmental Alternatives relating to radioactive waste management. They describe a number of different approaches (including fact finding missions, workshops and focus groups) taken in different projects. They emphasize that the decision process should be sufficiently transparent to demonstrate that stakeholders attitudes have been taken into account in arriving at the final decision. An overly complex process can be counter-productive.

Bruce (2006) applies the deductive approach to collaboration and negotiation and suggests seven interesting hypotheses:

- Hypothesis 1. If the parties hold widely divergent views, it is unlikely that they will appear to share common interests. That is, it is unlikely that they will agree concerning the direction of changes to any initial proposals.

- Hypothesis 2. Most negotiations between parties will take the form of "trades". Furthermore, the probability that such trades will take place will not be affected by the degree to which the initial allocation of resources is considered to be undesirable; but will be influenced by the cost of the negotiation process. 
- Hypothesis 3. If the policy that the government will select in the absence of collaboration is known to the parties, the outcome they adopt will be strongly influenced by that policy even if the parties reach consensus through open and unfettered bargaining.

- Hypothesis 4. If the parties are uncertain about the policy that will be imposed if they fail to reach agreement (and are risk averse), but share similar perceptions concerning the probabilities that various policies will arise, they will have a greater incentive to reach agreement than if they were certain about the default outcome.

- Hypothesis 5. If the parties have inconsistent expectations concerning the policy that will be imposed if they fail to reach agreement, there is a strong presumption that collaboration will fail.

- Hypothesis 6. If the government "frames" the issues to be negotiated (by restricting the set of possible outcomes), it may increase the probability that the parties will reach consensus. However, it will, at the same time, increase the probability that both parties will be dissatisfied with the outcome they have "chosen".

- Hypothesis 7. The parties' willingness to enter collaborative processes, and their ability to reach mutually beneficial outcomes, will not be affected by the parties' relative economic or political powers (as long as consensus is the decision rule).

He found these hypotheses were supported by the results of a questionnaire survey of people who had participated in a land use management decision making process.

\subsection{For compromise}

Some systems, called "Stakeholder DSS" have emerged that can be used by decision makers, technical experts and stakeholders to explore the consequences of combining either preference schemes or alternative scenarios in the hope of achieving mutually acceptable compromises. These are often made available and used by stakeholders over the internet. Haemaelaeinen et al. (2001) describe a framework for multicriteria modelling and support for a multi-stakeholder decision processes in relation to water level management in a regulated lake-river system in Finland. The stakeholders are involved in the decision process from formulating problem structuring stage to the group consensus seeking stage followed by a stage of seeking public acceptance for the policy. The framework aims at creating an evolutionary learning process. It also focuses on a new interactive method for finding and identifying Pareto-optimal alternatives. Role playing experiments with students are used to test the practical applicability of a negotiation support procedure called the method of improving directions. It describes the preference programming approach for the aggregation of the stakeholder opinions in the final evaluation of alternatives and consensus seeking.

\subsection{For reflection on priorities}

This is an aspect that is rarely addressed in DSS at the moment and has a number of practical difficulties. For instance if a decision support system encourages the changing of objectives as part of the process then can it be used to manipulate the final outcome. The boundary between such manipulation and facilitating the entire process is not clear with potential consequences for the credibility of the system. Of the few publications on the aspect of objectives, Makowski et al. (1997) have produced a system, applied to the Nitra River, in which aspiration-lead objectives can be modified as part of the multi-criteria decision making process.

\section{Conclusions}

This paper briefly traces the on-going movement of decision support methodology and the associated computation tools from a position in which they were complex and required specialist users and stand-alone computers to a position in which the complexity is hidden behind easy-to-use Graphical User Interfaces and can be used over the internet. This is associated with a shift in paradigm from a linear prescriptive process driven by technical and scientific experts to a new iterative, reactive, process giving more control to stakeholders. This paper outlines some multi-criteria methods suitable for use with the new paradigm and identified Concordance methods (such as ELECTRE) and the Analytical Hierarchy Process as appropriate tools. This expanded access to and use of decision support systems and related systems analysis methods facilitates public stakeholder participation and is a useful and welcome development and is compatible with the spirit of the WFD. It has provided an incentive and framework for new types of research projects that study how decisions are influenced (or not) by stakeholders' increased access to complex tools and sources of information. In the context of the WFD, such projects integrate water science and engineering with sociology in the expectation that the process will lead to more socially acceptable environmental decisions.

Acknowledgements. This review was done as part of the WINCOMS research project, sponsored by the Environmental Protection Agency of Ireland under its ERTDI programme and funded through Ireland National Development Plan.

Edited by: S. Barles 


\section{References}

Benayoun, R., Roy, B., and Sussman, N.: Manual de Referance du Programme ELECTRE, Note de Synthèse et Formation, No. 25, Direction Scientifique SEMA, Paris, 1966.

Bertalanffy, L. von: General System Theory: Foundations, Development, Applications, George Braziller, New York, 1968.

Bruce, C.: Modelling the environmental collaboration process: A deductive approach, Ecological Economics, 59, 275-286, 2006.

Bruen, M.: End-User level of service requirements, Carpe Diem Project report 11.2, available at: http://carpediem.am.ub. es/results/deliverables/Del_11.2_EndUSERREPORT2.pdf, (accessed Feb 2008), 2005.

Bruen, M.: Introduction to decision support systems, in: River basin modelling for flood risk mitigation, Taylor \& Francis, London, 235-248, 2006.

Burus, N.: Scientific allocation of water resources, American Elsevier Publishing Co, New York, 209 pp., 1972.

Checkland, P.: Soft systems methodology: a thirty year retrospective, Systems Research and Behavioural Science, 17(S1), S11S58, 2000.

Damart, S., Dias, L. C., and Mousseau, V.: Supporting groups in sorting decisions: Methodology and use of a multi-criteria aggregation/disaggregation DSS, Decis. Support Syst., 43(4), 14641475, 2007.

De Bono, E.: The Use of Lateral Thinking, Jonathan Cape, London, 1967.

De Neufville, R.: Applied systems analysis, McGraw-Hill, New York, 1990.

de Steiguer, J. E., Duberstein, J., and Lopes, V.: The Analytic Hierarchy Process as a Means for Integrated Watershed Management, in Proceedings of the First Interagency Conference on Research in the Watersheds, USDA, 736-740, 2003.

Dinka, D. and Lundberg, J.: Identity and role-A qualitative case study of cooperative scenario building, Int. J. Human-Computer Studies 64, 1049-1060, 2006

Eden, C.: Using Cognitive Mapping for Strategic Alternatives Development and Analysis (SODA), in Rational Analysis for a Problematic World, Wiley, Chichester, 1990.

Efstratiadis, A. and Koutsoyiannis, D.: An evolutionary annealingsimplex algorithm for global optimisation of water resource systems, in: Proceedings of the 5th International Conference on Hydroinformatics, IWA Publishing, UK, 1423-1428, 2002.

Galbraith, J. K.: A History of Economics: The Past as the Present, Penguin, UK, 1991.

Gill, P. E., Murray, W., and Wright, M. H.: Practical Optimization, Academic Press, London, 1981.

Giordano, R., Passarella, G., Uricchio, V. F., and Vurro, M.: Fuzzy cognitive maps for issue identification in a water resources conflict resolution system, Phys. Chem. Earth, 30, 463-469, 2005.

Giupponi, C., Mysiak, J., Fassio, A., and Cogan V.: MULINODSS: a computer tool for sustainable use of water resources at the catchment scale, Math. Comput. Simulat., 64, 13-24, 2004.

Haemaelaeinen, R. P., Kettunen, E., Ehtamo, H., and Marttunen, M.: Evaluating a Framework for Multi-Stakeholder Decision Support in Water Resources Management, Group Decis. Negot., 10(4), 331-353, 2001.

Hajkowicz, S. and Collins, K.: A Review of Multiple Criteria Analysis for Water Resource Planning and Management, J. Water Resources Management, 21(9), 1553-1566, 2007.
Hämäläinen, R. P.: Decisionarium - Aiding Decisions, Negotiating and Collecting Opinions on the Web, Journal of Multi-Criteria Decision Analysis, 12(2-3), 101-110, 2003.

Hannon, B. and Ruth, M.: Dynamic Modeling (Mac Version), Springer-Verlag, New York, 248 pp., 1994

Haseman, W. D., Nazareth, D. L. and Paul, S.: Implementation of a group decision support system utilising collective memory, Information and Management, 42, 591-605, 2005.

Heathcote, I. W.: Integrated Watershed Management: Principles and Practices, John Wiley and Sons, New York, 1998.

Jamieson, D.: An integrated, multi-functional approach to water resources management, Hydrolog. Sci. J., 31(4), 501-514, 1986.

Innes, J. E. and Booher, D. E.: Consensus building and Complex Adaptive Systems: A Framework for Evaluating Collaborative Planning, Journal of Planning Association, 65(4), 412-423, 1999.

Ison, R. and Watson, D.: Illuminating the possibilities for social learning in the management of Scotland's water, Ecology and Society, 12(1), 21, available at: http://www.ecologyandsociety. org/vol12/iss1/art21/ (accessed Feb 2008), 2007.

Janssen, M. A. and Goosen, H., and Omtzigt, N.: A simple mediation and negotiation support tool for water management in the Netherlands, Landscape Urban Plan., 78, 71-84, 2006.

Kalman, R. E.: A new approach to linear filtering and prediction problems, Transactions of the A.S.M.E., J. Basic-Eng-D, 82, 3545, 1960.

Kearney, A. and Kaplan, S.: Toward a methodology for the measurement of knowledge structures of ordinary people - The conceptual concept cognitive map (3CM), Environ. Behav., 29, 385415, 1997.

Keeney, R. L. and Raiffa, H.: Decisions with Multiple Objectives: Preferences and Value Trade-Offs, Cambridge University Press, Cambridge, UK, 1993.

Kelly, G. A.: The psychology of personal constructs, Norton, New York, 1955.

Kemp, R. V., Bennett, D. G., and White, M. J.: Recent trends and developments in dialogue on radioactive waste management: Experience from the UK., Environment International, 2006.

Kolkman, M. J., Kok, M., and van der Veen, A.: Mental model mapping as a new tool to analyse the use of information in decisionmaking in integrated water management, Phys. Chem. Earth, 30, 317-332, 2005.

Limayem, M., Banerjee, P., and Ma, L.: Impact of GDSS: Opening the black box, Decis. Support Syst., 42(2), 945-957, 2006.

Lourenco, R. P. and Costa, J. P.: Incorporating citizens' views in local policy decision making processes, Decis. Support Syst., 43(4), 1499-1511, 2007.

Makowski, M., Somlyody, L. and Watkins, D.: Multiple Criteria Analysis for Regional Water Quality Management - the Nitra River case, Working paper 95-022, IIASA, Austria, 1997.

Massam, B.: Spatial Search, Pergamon Press, 1988.

May, R. M.: Will a Large Complex System be Stable?, Nature, 238, 413-414, 1974.

Miller, G. A.: The Magical Number Seven, Plus or Minus Two: Some Limits On Our Capacity For Processing Information, The Psychological Review, 63, 81-97, 1956.

Moreno-Jimenez, J. M. and Polasek, W.: e-Democracy and knowledge. A multicriteria framework for the new democratic era, Journal of Multi-Criteria Decision Analysis, 12(2-3), 163-176, 
2003.

Odum, H.: Ecological and General Systems: An introduction to systems ecology, Colorado University Press, Colorado, 1994.

Odum, H. and Odum, E.: Modelling for all scales - An introduction to systems simulation, Academic Press, New York, 2000.

Osborn, A. F.: Applied imagination: Principles and procedures of creative problem solving, New York, Charles Scribner's Sons, 1963.

Ossenbrugger, P. J.: Systems Analysis for Civil Engineers, Wiley, New York, 1984.

Pahl-Wostl, C.: Transitions towards adaptive management of water facing climate and global change, Water Resources Management, 21, 49-62, 2007a.

Pahl-Wostl, C.: The implications of complexity for integrated resources management, Environ. Modell. Softw., 22, 561-569, $2007 b$.

Regan, H. M., Colyvan, M., and Markovchich-Nicholls, L.: A formal model for consensus and negotiation in environmental management, J. Environ. Manage., 80, 167-176, 2006.

Rios-Insua, D., Holgado, J., and Morena, R.: Multicriteria eNegotiation Systems for e-Democracy, Journal of Multi-Criteria Decision Analysis, 12, 213-218, 2003.

Rogers, M. G., Bruen, M., and Maystre, L.-Y.: ELECTRE and Decision Support: Methods and Applications in Engineering and Infrastructure Investment, Kluwer Academic Publishers, Boston, 208 pp., 1999.

Rogers, M. G. and Bruen, M. P.: Non-monetary Decision-Aid techniques in EIA - An Overview, Paper 10746, Proceedings of the Institution of Civil Engineers, Municipal Engineer, 109, June, 88-103, 1995.

Rogers, M. G. and Bruen, M. P.: A New System for Weighting Criteria within Electre, Eur. J. Oper. Res., 107(3), 552-563, 1998.

Roy, B.: Classement et choix en présence de points de vue multiples (la méthode ELECTRE), La Revue d'Informatique et de Recherche Opérationelle (RIRO), 8, 57-75, 1968.

Roy, B., Slowinski, R., and Treichel, W.: Multicriteria programming of water supply systems for rural areas, Water Resour. Bull., 28, 13-31, 1992.

Rubio, J. A., Rios-Insua, D., Rios, J., and Fernandez, E.: Quixote: Supporting Group Decisions Through the Web, in: EGovernment Towards Electronic Democracy, Proceedings of an International Conference, Bolzano, Springer, Berlin, 225-234, 2005.

Saaty, T. L.: The Analytic Hierarchy Process, McGraw-Hill, 1980.

Saaty, T. L.: A Scaling for Priorities in Hierarchical Structures, J. Math. Psychol., 15, 207-218, 1977.
Sharma, M. and Norton, B. G.: A policy decision tool for integrated environmental assessment, Environ. Sci. Policy, 8(4), 356-366, 2005.

Shirani, A. I.: Sampling and pooling of decision-relevant information: Comparing the efficiency of face-to-face and GSS supported groups, Information and Management, 43, 521-529, 2006.

Srdjevic, B.: Linking analytic hierarchy process and social choice methods to support group decision-making in water management, Decis. Support Syst., 42(4), 2261-2273, 2007.

Tan, C. O. and Ozesmi, U.: A generic shallow lake ecosystem model based on collective expert knowledge, Hydrobiologia, 563, 125-142, 2006.

Tang, S. L. and Ellis, K. V.: Wastewater Treatment Optimisation Model for Developing World. Part I: Model Development, ASCE Journal of Environmental Engineering, 117(4), 501-518, 1991.

Tippett, J.: Policies and Tools for Sustainable Water Management in the European Union, Environ. Modell. Softw., 20(2), 119-139, 2005.

Tippett, J.: A participatory protocol for ecologically informed design within river catchments, Ph.D. thesis, School of Planning and Landscape, University of Manchester, UK, 2004.

Tippett, J., Searle, B., Pahl-Wostl, C., and Rees, Y.: Social learning in public participation in river basin management - early findings from HarmoniCOP European case studies, Environ. Sci. Policy, 8(3), 287-299, 2005.

Triantaphyllou, E.: Two New Cases of Ranking Reversals When the AHP and Some of Its Additive Variants Are Used that do not Occur with the Multiplicative AHP, Multi-Criteria Decision Analysis, 10, 11-25, 2001

Turoff, M., Hiltz, S. R., Cho, H. K., Li, Z., and Wang, Y.: Social Decision Support Systems (SDSS), in: Proc. 35th Hawaii International Conference on Systems Science, Vol. 1, paper no. 11, 2002.

Wang, X. and Triantaphyllou, E.: Ranking irregularities when evaluating alternatives by using some ELECTRE methods, Omega, 36, 45-63, 2008

Wilson, D. and Droste, R.: Design consideration for watershed management decision support systems, Water Quality Res. J. Canada, 35(2), 163-188, 2000.

Vatn, A.: Resource regimes and cooperation, Land Use Policy, 24(4), 624-632. 2007.

Vincke, P.: Multicriteria Decision Aid, John Wiley, Van Delft and Nijkamp, 1992. 